Rev Inv Vet Perú 2018; 29(2): 692-698

http://dx.doi.org/10.15381/rivep.v29i2.14485

\title{
Comunicación
}

\section{Ectrodactilia en un Beagle: manejo quirúrgico}

\author{
ECTRODACTYLY IN A BEAGLE: SURGICAL MANAGEMENT
}

Eben A. Salinas ${ }^{1,3}$, Edith R. Chávez ${ }^{1}$, Ricardo E. Timmermann ${ }^{2,4}$

\section{ReSUMEN}

Se reporta el caso de un Beagle hembra de 5 meses con cojera del miembro anterior derecho y un defecto de separación entre el segundo y tercer dedo. En el examen radiográfico se observó hipoplasia del hueso carporradial y del segundo metacarpiano, y ausencia del primer dedo. Además, presentó una hendidura con contenido de tejido blando entre el segundo y tercer metacarpiano. Los hallazgos fueron compatibles con ectrodactilia unilateral. Se realizó una cirugía reconstructiva mediante una artrodesis pancarpal, con relleno de hueso esponjoso y utilizando un sistema de fijación esquelética externa. Se restableció completamente la función del miembro a las 10 semanas.

Palabras clave: Beagle; ectrodactilia; artrodesis; disostosis

\section{AbSTRaCt}

The case of a 5-month-old female Beagle with lameness of the right anterior limb and a separation defect between the second and third fingers is reported. In the radiographic examination, hypoplasia of the carporradial bone and of the second metacarpal, and absence of the first finger was observed. In addition, the patient presented a cleft with soft tissue content between the second and third metacarpal. The findings were compa-

\footnotetext{
${ }^{1}$ Carrera de Medicina Veterinaria y Zootecnia, Universidad Cientifica del Sur, Lima, Perú

${ }^{2}$ Healing Hands - Salud y Rehabilitación Física Veterinaria, Lima, Perú

${ }^{3}$ E-mail: esalinasc@cientifica.edu.pe

4.E-mail: ricardo@hhvet.org
}

Recibido: 10 de agosto de 2017

Aceptado para publicación: 15 de enero de 2018 
tible with unilateral ectrodactyly. Reconstructive surgery was performed through a pancarpal arthrodesis, with cancellous bone filling and using an external skeletal fixation system. The limb's function was completely restored at 10 weeks.

Key words: Beagle; ectrodactyly; arthrodesis; dysostosis

\section{INTRODUCCIÓN}

Las disostosis son alteraciones congénitas de los mamíferos que consisten en un defecto en el desarrollo total o parcial de un hueso. Las disostosis resultan de fallas en el desarrollo del tejido mesenquimalóseo, de la transformación del hueso mesenquimal en cartílago o de la conversión del cartílago en hueso (Towle y Breur, 2004). Las disostosis del esqueleto axial incluyen alteraciones como hemivértebra, vértebra en bloque, vértebra mariposa y espina bífida. Las disostosis apendiculares incluyen hemimelia, amelia, dimelia, polidactilia y ectrodactilia (Towle y Breur, 2012).

La ectrodactilia (ED) es una anomalía poco común que involucra una deficiencia para-axial inusual del desarrollo embrionario de la porción distal del miembro anterior (Towle y Breur, 2004). Se establece que su presentación se basa en una deficiencia específica de la cresta apical ectodérmica del esbozo del miembro primordial, involucrando a los precursores embrionarios de la extremidad anterior (Carrig et al., 1981; Barrand, 2004). La ED se caracteriza clínicamente por la presencia de un tejido blando anormal, que produce una separación o hendidura desde el extremo proximal de los dedos hacia los huesos metacarpianos. Esta separación puede extenderse incluso hasta la articulación antebraquiocarpiana (Ferreira et al., 2007). La ED se ha reportado en varias especies de mamíferos, incluyendo el humano (Elliott et al., 2006).
En el canino, las malformaciones intrínsecas, así como la interrupción del desarrollo de las células óseas entre los 23 y 35 días de gestación, pueden resultar en anomalías apendiculares como la ED (Evans, 1993). Es por esta razón que la ED puede asociarse con hipoplasia, aplasia y malformación de uno o más huesos del antebrazo, carpo, metacarpo y dedos (Carrig et al., 1981; Towle y Breur, 2012).

La ED se ha reportado principalmente como unilateral, aunque hay reportes de presentación bilateral y también asociada a alteraciones de la columna, como es el caso de la hemivértebra (Carvallo et al., 2010). La ED puede ser diagnosticada con el examen físico; sin embargo, para caracterizar y evaluar la gravedad de las anormalidades se requiere del estudio radiográfico con vistas ortogonales. Radiográficamente en un miembro con ED se puede identificar una hendidura entre los huesos metacarpianos, con mayor frecuencia entre los huesos I y II, pudiendo también aparecer dicha hendidura entre los otros huesos metacarpianos (Carrig et al., 1981; Towle y Breur, 2004). Estas alteraciones pueden acortar la longitud de la ulna, separándola del radio y produciendo luxación del codo.

Los pacientes afectados por ED pueden desarrollar desde una discapacidad leve a una incapacidad severa, con pérdida de la función del miembro afectado. Para plantear las opciones de tratamiento, es importante determinar la severidad de los signos clínicos y la condición de las estructuras óseas pre- 
sentes en la región afectada. El objetivo del presente reporte fue describir la presentación de un caso clínico, así como su tratamiento quirúrgico ortopédico.

\section{Caso Clínico}

Una perra Beagle hembra, de 5 meses de edad, fue referida por cojera y malformación de la porción distal del miembro anterior derecho. En el examen clínico se evidenció una hendidura con un notorio desplazamiento entre los huesos metacarpianos II y III, y con ausencia del primer dedo. El antebrazo derecho presentaba una menor longitud en comparación con el miembro contralateral y la masa muscular en esta región estaba disminuida (Figura 1).

En el examen radiográfico, la hendidura entre los metacarpianos II y III era completa hasta la epífisis del radio. La región comprendida por la hendidura solo presentaba tejido blando. En la fila proximal y distal del carpo se identificó al hueso carporradial y

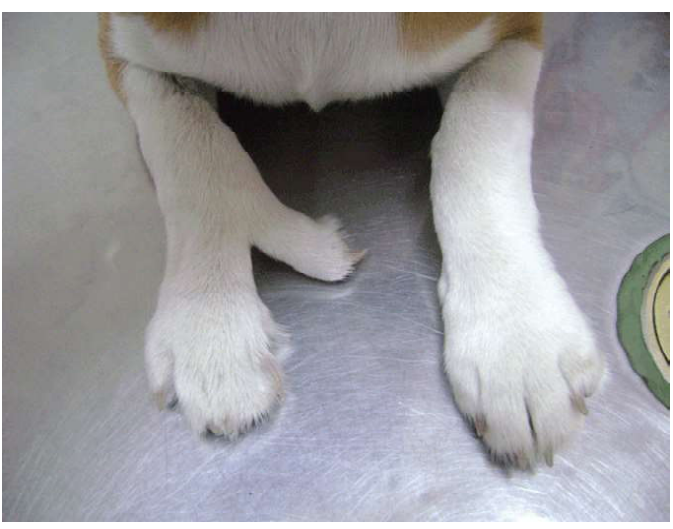

Figura 1. Imagen frontal de los miembros anteriores de un Beagle hembra de 5 meses. En el miembro anterior derecho, se observa una hendidura longitudinal con desviación medial del segundo metacarpiano del miembro anterior derecho y una leve disminución de la longitud antebraquial y digital segundo hueso carpiano desviados medialmente y con características de hipoplasia. A excepción del primer carpiano, los demás huesos del carpo estaban presentes con leves alteraciones en su forma y tamaño. Estas alteraciones producían una severa inestabilidad de la articulación (Figura 2 A,B).

Con base en las alteraciones identificadas en el paciente, se planteó el diagnóstico de ectrodactilia de presentación leve. Se procedió a una cirugía reconstructiva mediante una artrodesis pancarpiana. Como medicación pre-anestésica, se administró morfina a una dosis de $0.5 \mathrm{mg} / \mathrm{kg}$, midazolam a $0.2 \mathrm{mg} / \mathrm{kg}$ y cefalotina a $30 \mathrm{mg} / \mathrm{kg}$, todos por vía endovenosa. En el miembro afectado se realizó un bloqueo nervioso del plexo axilar por infiltración con lidocaína al 2\%. Para la inducción anestésica se usó propofol a $5 \mathrm{mg} / \mathrm{kg}$ por vía endovenosa y el mantenimiento anestésico se realizó con sevoflurano en oxígeno al $100 \%$, usando un circuito de no reinhalación.

Se realizó una incisión sobre la línea media de la superficie dorsal del carpo, extendiéndola entre la articulación carporradial hasta la articulación carpometacarpiana. Se abordaron las estructuras blandas hasta la cápsula articular que recubría las articulaciones antebraquiocarpiana, intercarpiana y carpometacarpiana. Utilizando un taladro eléctrico de bajas revoluciones se procedió a eliminar la superficie articular de cada articulación. En el mismo tiempo quirúrgico, de manera aséptica, se obtuvo un autoinjerto de hueso esponjoso de la cresta iliaca, el cual se insertó en las superficies denudadas de cada articulación (Fossum, 2009).

En el carpo se colocaron dos agujas en disposición transversal, con la primera aguja incluyendo el hueso carporradial y el hueso carpo ulnar. El segundo implante incluyó el hueso carporradial a la región proximal de los huesos metacarpianos IV y V. El objetivo de estos implantes fue brindar mayor estabilidad al carpo y disminuir la hendidura pre- 

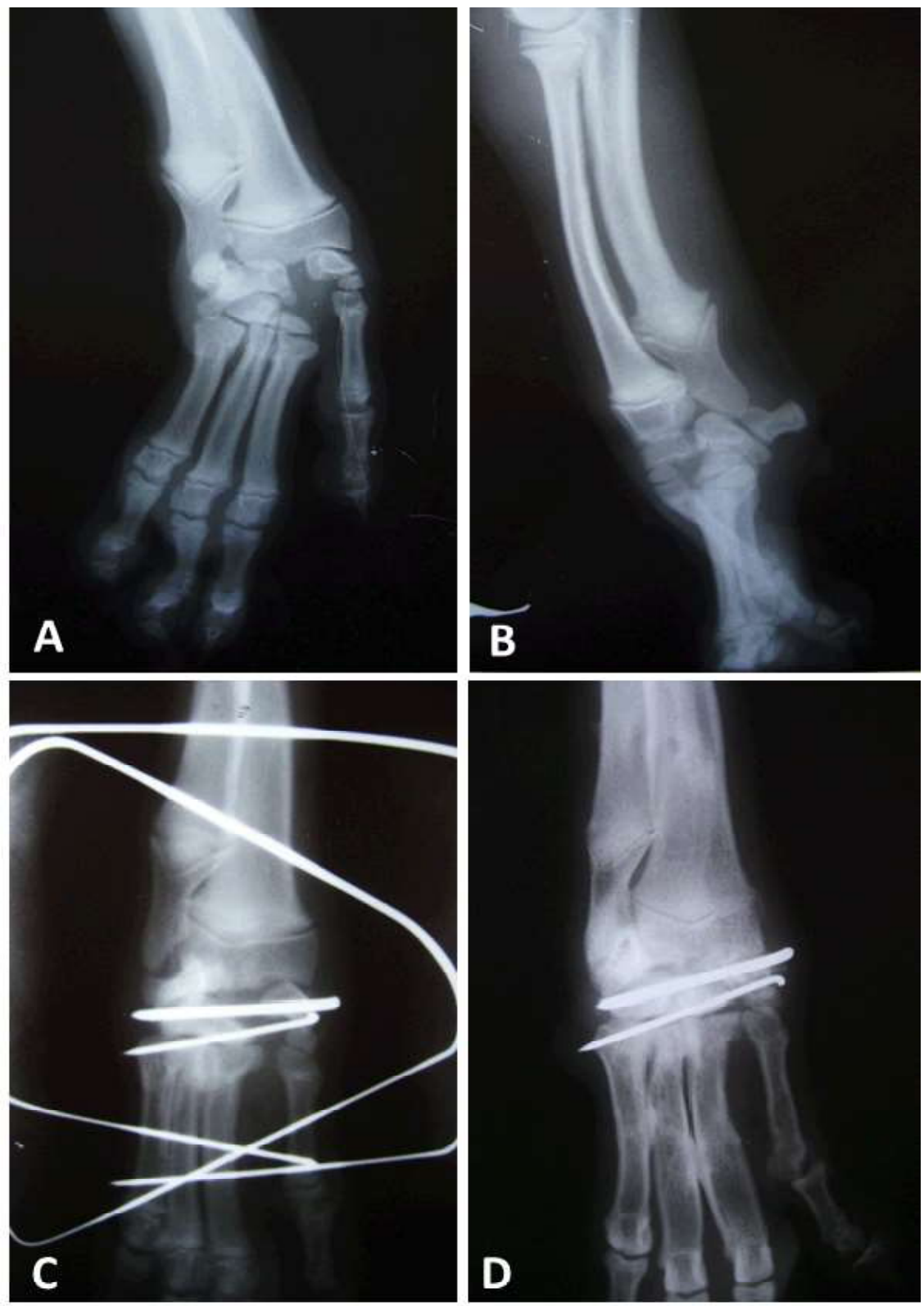

Figura 2. Radiografías de la región distal del miembro anterior derecho de un Beagle hembra de 5 meses. A y B (incidencias dorso palmar y medial lateral): hendidura entre metacarpianos II y III, hipoplasia del hueso carporradial y severa inestabilidad articular. C: Radiografía post quirúrgica inmediata de la artrodesis pancarpal: disminución de hendidura en metacarpos mediante agujas que incluyen el hueso carporradial. Se aprecian las agujas transcorticales del fijador esquelético externo. D: Imagen post quirúrgica a las 10 semanas luego del retiro del fijador esquelético externo. Artrodesis y remodelación ósea completa

sente entre el segundo y el resto de metacarpianos. Se realizó una incisión en forma de $\mathrm{V}$ entre el segundo y tercer metacar- piano, y a continuación se suturaron los tejidos blandos de ambos dedos logrando disminuir la brecha y volviéndolos paralelos entre sí. 
Finalmente, se estabilizó la artrodesis con una extensión de 10 grados utilizando un fijador externo de tipo IIB. Para tal fin, se utilizaron cinco agujas de Kirschner, insertándolas de manera percutánea-transcortical en un plano transverso y oblicuo, proximalmente en el radio y distalmente en los metacarpianos (Figura 2C). Los implantes se unieron en el exterior por medio de una barra conectora moldeada de metil metacrilato. Se realizó la síntesis de la cápsula articular, tejidos blandos y piel de manera tradicional. La herida se mantuvo cubierta con un vendaje, el manejo del dolor se realizó con una asociación entre tramadol a una dosis de $3 \mathrm{mg} / \mathrm{kg}$ cada 12 horas y carprofeno a $2.2 \mathrm{mg} / \mathrm{kg}$ cada 12 horas. Además, se administró cefalexina a una dosis de $25 \mathrm{mg} / \mathrm{kg}$ como profilaxis antibiótica.

El paciente sustentó parcialmente el miembro intervenido a los siete días. La sustentación completa del miembro se evidenció a la segunda semana. Se realizaron los estudios radiográficos a las 4, 6 y 8 semanas posteriores a la cirugía. Se retiró el fijador esquelético externo a las 10 semanas, logrando la artrodesis y la remodelación ósea esperada (Figura 2D).

\section{Discusión}

La ED es una afección congénita reportada como infrecuente en el perro. Los reportes de esta alteración son de casos únicos sin referencia a la etiología. Se ha demostrado la ED hereditaria en el gato debido a un gen autosómico dominante (Schneck, 1974); sin embargo, esta relación no se ha logrado establecer en el perro (Innes et al., 2001).

En el caso presentado, fue determinante el uso de la herramienta radio-diagnóstica. Si bien la ED puede ser diagnosticada durante el proceso del examen clínico, es imprescindible realizar el estudio por imágenes del miembro afectado. Las radiografías deben tomarse perpendiculares entre sí y deben incluir todo el miembro anterior, ya que son muy frecuentes las complicaciones ortopédicas en hombro, codo y antebrazo (Ferreira et al., 2007).

Existen pocos informes sobre el tratamiento quirúrgico de la ED en animales de compañía (Innes et al., 2001; Pisoni et al., 2014). La decisión quirúrgica será adoptada por el cirujano con base en la gravedad de la lesión y las estructuras óseas involucradas en la deformidad. Los objetivos de la cirugía pueden ser paliativos o reconstructivos. La cirugía paliativa incluye la amputación total o parcial de extremidades o dedos severamente alterados que interfieren con la ambulación o son causa de heridas por automutilación. Las cirugías reconstructivas tienen por objetivo rescatar la función del miembro afectado a través del realineamiento mediante artrodesis pancarpiana o parcial (Kerrigan y Robinson, 2016).

En el caso descrito, el paciente presentó una ED leve, toda vez que no había presentación de alteraciones ortopédicas severas. En la literatura científica se describen diversas presentaciones graves de la ED, como la ausencia de metacarpianos o la luxación de la articulación del codo; condiciones que producen severa incapacidad en los pacientes (Carvallo et al., 2010; Di Dona et al., 2016).

La decisión quirúrgica para la mejora sostenida del paciente fue una artrodesis pancarpiana. Esta técnica genera una fusión quirúrgica de una articulación para formar una anquilosis ósea (Piermattei y Flo, 1999). La artrodesis se puede realizar para tratar satisfactoriamente la hiperextensión y colapso de la articulación carpiana (Fossum, 2009). El uso del sistema de fijación externa fue adecuado para la estabilización de la artrodesis. Se han reportado muchas ventajas de los fijadores externos en ortopedia veterinaria, al ser un método poco cruento y alejado del foco fracturario o lesionado (Pistani, 1994), y tener un diseño acorde al paciente que con- 
tribuye a promover un inicio temprano de la movilidad y uso del miembro (Mejía et al., 2012). La decisión de emplear esta técnica estuvo en función del tamaño y edad del paciente, factores que contribuyeron positivamente a la recuperación exitosa. En pacientes de gran tamaño y peso, es más recomendable el uso de placas que incluyan al radio y tercer metacarpiano (Dee, 1992).

Con el uso de esta técnica se lograron los resultados esperados, mejorando la función del miembro y evitando el desarrollo prematuro de complicaciones articulares en regiones proximales al carpo, como el codo y hombro. El manejo del paciente fue enteramente ambulatorio, lo cual contribuyó positivamente a disminuir los tiempos de hospitalización y los costos del tratamiento. Se corrobora la utilidad de la artrodesis pancarpal como una alternativa a tener en cuenta para el tratamiento de la ectrodactilia en los canes.

\section{Literatura Citada}

1. Barrand $K R, 2004$. Ectrodactyly in a West Highland white terrier. J Small Anim Pract 45: 315-318. doi: 10.1111/j.17485827.2004.tb00243.x

2. Carrig CB, Wortman JA, Morris EL, Blevins WE, Root CR, Hanlon GF, Suter PF. 1981. Ectrodactyly (split-hand deformity) in the dog. Vet Radiol Ultrasound 22: 123-144. doi: 10.1111/ j.1740-8261.1981.tb01363.x

3. Carvallo F, Domínguez A, Morales P. 2010. Bilateral ectrodactyly and spinal deformation in a mixed-breed dog. Can Vet J 51: 47-49.

4. Dee JF. 1992. Artrodesis del carpo. En: Summer-Smith G (ed). Toma de decisiones en cirugía ortopédica de pequeños animales. México: Interamericana McGraw Hill. p 72-73.

5. Di Dona F, Della Valle G, Meomartino L, Lamagna F, Fatone G. 2016. Congenital deformity of the distal extremities in three dogs. Open Vet J 6: 228-233. doi: 10.4314/ovj.v6i3.11
6. Elliott A, Reed M, Evans J. 2006. Triphalangeal thumb in association with split hand/foot. A phenotypic marker for SHFM3? Birth Defects Res A 79: 5861. doi: 10.1002/bdra.20317

7. Evans H. 1993. Prenatal development. In: Miller's anatomy of the dog. Philadelphia, USA: WB Saunders. p 32-97.

8. Ferreira M, Alievi M, Beck C, Voll J, Muccillo M, Gomes C. 2007. Ectrodactilia em cão: relato de caso. Arq Bras Med Vet Zootec 59: 910-913. doi: 10.1590/S0102-09352007000400015

9. Fossum TW. 2009. Enfermedades articulares. En: Cirugía de pequeños animales. $3^{\mathrm{a}}$ ed. España: Elsevier. p 11431315.

10. Innes J, McKee W, Mitchell R, Lascelles B, Johnson K. 2001. Surgical reconstruction of ectrodactyly deformity in four dogs. Vet Comp Orthop Traumatol 14: 201-209.

11. Kerrigan S, Robinson D. 2016. Juvenile orthopedic disease in dogs \& cats. Part 2: congenital \& neonatal orthopedic diseases. Today's Vet Pract 6(5). [Internet]. Disponible en: http:// todaysveterinarypractice.navc.com/ juvenile-orthopedic-disease-in-dogscatspart-2-congenital-neonatalorthopedic-diseases/

12. Mejía M, Parra Y, Polania S. 2012. Corrección quirúrgica de una luxo-fractura congénita de carpo con un fijador biplanar-bilateral con banda de tensión ligamentaria. Redvet 13(2). [Internet]. Disponible en: http://www.veterinaria. org/revistas/redvet/n020212/021201.pdf

13. Piermattei D, Flo G.1999. Manual de ortopedia y reparación de fracturas de pequeños animales. $3^{a}$ ed. España: McGraw-Hill-Interamericana. $756 \mathrm{p}$.

14. Pisoni L, Del Magno S, Cinti F, Dalpozzo B, Bellei E, Cloriti E, Joechler M. 2014. Surgical induction of metacarpal synostosis for treatment of ectrodactyly in a dog. Vet Comp Orthop Traumatol 27: 166-171. doi: 10.3415/ VCOT-13-01-0019 
15. Pistani JR. 1994. Uso de los fijadores externos en ortopedia y traumatología veterinaria. Rev Asoc Argent Ortop Traumatol 59(5): 81-90.

16. Schneck GW. 1974. Two cases of congenital malformation (peromelus ascelus andectrodactyly) in cats. Vet Med Small Anim Clin 69: 1025-1026.
17. Towle H, Breur G. 2004. Dysostoses of the canine and feline appendicular skeleton. J Am Vet Med Assoc 225:1 6851692. doi: 10.2460/javma.2004.225.1685

18. Towle H, Breur G. 2012. Miscellaneous orthopedic conditions. En: Tobias KM, Johnston SA (eds). Veterinary surgery: small animal. St. Louis: Elsevier Saunders. p 1112-1126. 